\title{
HYDROGEN INDUCED CRACKING IN LINEPIPE STEELS
}

\author{
M.T. Shehata \\ Materials Technology Laboratory/CANMET \\ Natural Resources Canada \\ 568 Booth Street, Ottawa, Ontario, Canada K1A 0G1
}

Line-pipe steels in sour service are susceptible to hydrogen induced cracking (HIC) which depends on both metallurgical and environmental factors (1). On of the important metallurgical factors is the presence of non-metallic inclusions in the line-pipe steel. Hydrogen atoms diffuse easily through the pipe wall and accumulate at internal micro-voids which has previously formed at the interface of non-metallic inclusions. Hydrogen induced cracks form as a result from the internal pressure of the accumulated molecular hydrogen. A typical example of such a crack is shown in figure 1. This particular crack is termed a blister crack since it appears as a blister on the outside surface of the pipe where the material is lifted by the hydrogen pressure.

Planar arrays of fragmented inclusions were found to be connected to the formation of large HIC (1). Figure 2 shows a montage of SEM micro-graphs following a long string of fragmented inclusions on a polished metallographic section. In order to assess the relationship between HIC and non-metallic inclusions and in particular planar arrays of aligned inclusions, it was desired to obtain quantitative metallographic information for the inclusion population in a number of linepipe steels that were assessed for HIC. This was achieved by image analysis where two types of inclusion geometry were identified and measured separately, namely, long strings of fragmented inclusions and other dispersed inclusions. This is illustrated by the end map shown in figure 3. The end map is basically a low magnification assembly for the metallographic information observed at high magnification, which indicates the overall picture of the inclusion population through the wall thickness of the line-pipe steel. Excluding a band about $0.5 \mathrm{~mm}$ wide at the edge, the sample is covered by 12 microscopic fields through the wall thickness $(6 \mathrm{~mm})$ by 46 fields in the longitudinal direction (each field is 400x400 micrometers). It should be noted that the end map, shown in figure 3 provides the identification of susceptible area for hydrogen induced cracks on the sample as indicated by the solid lines indicating the presence of long strings of fragmented inclusions.

The total length of hydrogen induced cracks in a number of line pipe steels were determined using NACE standard TM-02-84(2) and the results were reported elsewhere (3). When the total length of cracks per unit area is plotted against the total length of planar arrays of inclusion per unit area, a good correlation between the length of cracks and the length of long strings of inclusions is obtained.

\section{REFERENCES}

1. M.T. Shehata, G.J. Biefer and J.D. Boyd, Microstructural Science Vol 13 (1986) 263-267

2. NACE Standard TM-02-84, "test Method - Evaluation of Pipeline Steels for Resistance to Stepwise Cracking", Houston, Texas, NACE 1984.

3. M. Elboujdaini, M.T. Shehata, V.S. Sastri, R.W. Revie and R.R. Ramsingh, Corrosion 98, Paper No. 748, Nace International 1998. 


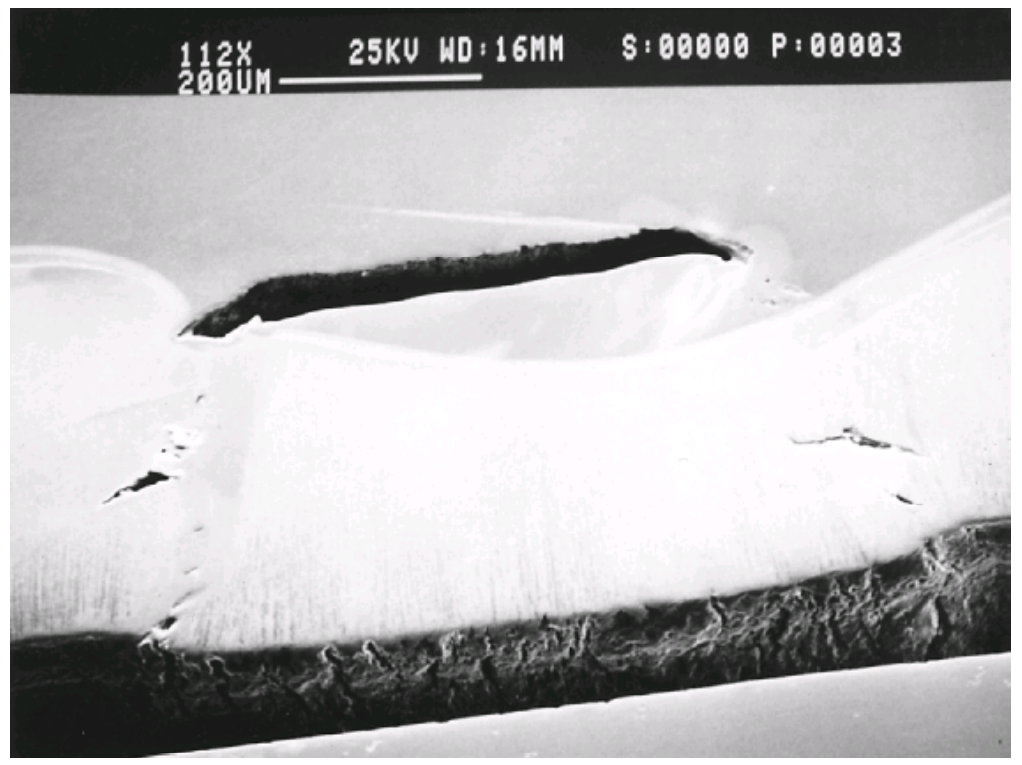

Figure 1. SEM

photomicrograph of a crosssection through the pipe wall showing a typical blister crack where the material is lifted by the pressure of hydrogen.

Figure 2. A montage of SEM photomicrographs showing a long string of fragmented inclusions on a polished metalographic section. Note the common areas A,B and C in the micrograph.
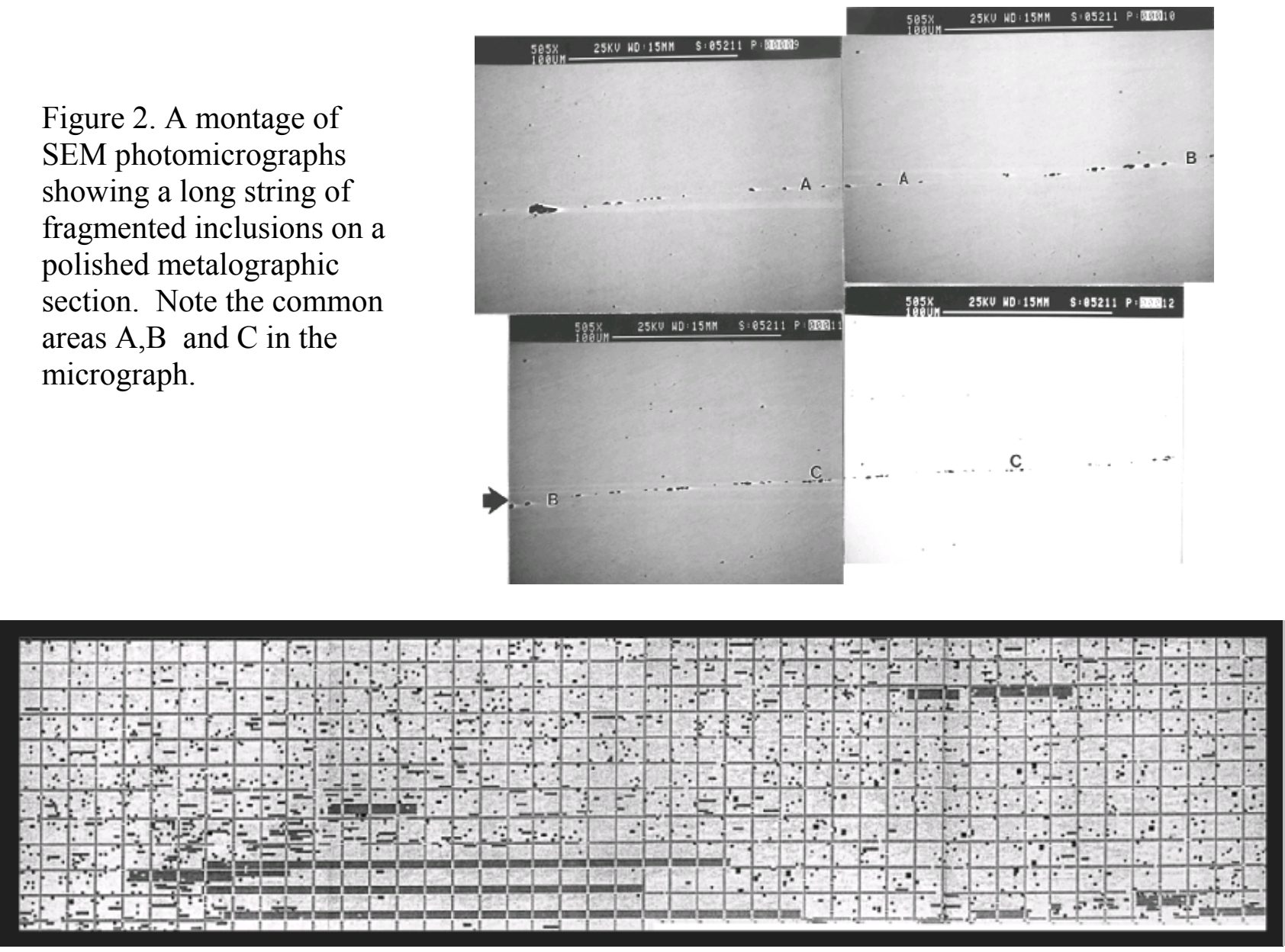

Figure 3. An End Map of 12x46 microscopic fields showing the overall picture of the metallographic examination through the wall thickness of $6 \mathrm{~mm}$ by image analysis. Long strings of fragmented inclusions are identified in the map by thick solid lines. 